\title{
Associated Persons Medical History Domain
}

National Cancer Institute

\section{Source}

National Cancer Institute. Associated Persons Medical History Domain. NCI Thesaurus.

Code C147173.

A domain utilized for the submission of medical history records related to persons associated with the study subject. 